\title{
Perceived Availability of and Attitudes toward Healthy Food Choices in Assisted-Living Facilities in Kansas
}

Pei Liu

Department of Hospitality Management and Dietetics

Kansas State University

and

Junehee Kwon

Department of Hospitality Management and Dietetics

Kansas State University

\begin{abstract}
The purpose of this project was to assess perceived availability of healthy food choices and examine relationships between attitudes, subjective norms (SN), perceived behavior control $(P B C)$, and behavior intention (BI) to consume healthy food at assisted-living facilities using the Theory of Planned Behavior (TpB). An instrument based on the theory of planned behavior (TpB) was developed and tested with 115 elderly residents in eight facilities in Kansas. The results showed that attitudes toward healthy food and SN were positively associated with consumption intention. However, PBC among residents was not a significant predictor of the intention to select healthy food choices. The results of this study confirmed that elderly population living in elder care facilities desires and are willing to choose healthy food choices but feel the lack of their control over food choices. Managers from these facilities may utilize this data to recognize their residents' needs, investigate ways to improve residents' diets, and potentially increase healthy food consumption of their elderly clients.
\end{abstract}

Keywords: Healthy food, elderly, assisted-living facilities, the theory of planned behavior, perceived availability, food choices

\section{INTRODUCTION}

According to U.S. Census Bureau (2000), 35 million people were aged 65 and older in 2000. As Baby Boomers reach the age of 65, the elderly population will continue to increase in the next 20 years. The Department of Health and Human Service (DHHS) projects that the elderly population (i.e., 65 and older) will double in size by 2030 compared to 2000 , accounting for $20 \%$ of the U.S. population. This increase in the elderly population will have an impact on many aspects of our society, and meeting the needs of the elderly will become increasingly important (DHHS, 2010).

Along with the aging population, the percentage of the obese population continues to increase in the U.S. Over two-thirds of all adults in the U.S. are overweight and half of them are clinically obese (Ogden, Carroll, Curtin, McDowell, Tabak, \& Flegal, 2006). The elderly population is not immune from this trend. Data from1988-1994 showed that $27 \%$ of women and $24 \%$ of men age $65-74$, and $19 \%$ of women and $13 \%$ of men age 75 or older were obese. These numbers significantly increased in 2005-2006 as 37\% of women and 33\% of men age $65-74$, and $24 \%$ of women and $25 \%$ of men age 75 and older were obese (DHHS, 2010). The percentage of 
obese elderly age 65-74 exceeds the population average of obesity (Ogden et al.). The obesity epidemic is a serious health concern because it increases the risk of many chronic diseases and health conditions such as hypertension, diabetes and certain types of cancer (Harvard Men's Health Watch, 2006).

Body weight is influenced by genetics, energy intake and energy expenditure. Food choice is an important factor affecting energy intake and nutrition quality. A healthy, nutritious diet could reduce the risk of many chronic diseases (DHHS, 2010). According to the Healthy Eating Index (HEI) 2005, people age 65 years and older need to increase intakes of whole grains, milk products, and vegetables and decrease consumption of sodium and saturated fat (Guenther, Reedy, Krebs-Smith, Reeve, \& Basiotis, 2007). The 2005 USDA Dietary Guidelines for Americans defines healthy food as "a plant or animal product that provides essential nutrients and energy to sustain growth, health and life while satiating hunger" (Access to Healthy Foods Coalition, 2009, para. 4). Consuming appropriate amounts of healthy food provides the necessary nutrients, helps prevent acquiring diseases, gives individuals more energy, and improves health status (CDC, 2009).

"What is needed for American elderly is not length of life but quality of life" (Hautvast, De, \& Van, 1992, p. 484). An increasing number of the elderly is seeking independent or assistedliving housing in continuing care retirement communities (CCRC). These facilities provide support for daily activities including foodservice in a place where they feel sense of community (Krout, Moen, Holmes, Oggins, \& Bowen, 2002). In order to improve the quality of life for the elderly, managers in assisted-living and/or CCRC facilities need to understand residents' needs and desires.

Baby Boomers are characterized as independent, goal-oriented, conscientious regarding wellness, and pleasure-seeking (Baby Boomer Care, 2010; Kane, 2010; Patterson, 2004). Consequently, the needs and wants of these elderly concerning their desire for healthy food choices must be understood in order to provide customer satisfaction. However, currently little is known about the perceptions about healthy food choices and availability among the elderly living in CCRC.

Understanding attitudes, perceived barriers, and behavior intentions toward consuming healthy food may help foodservice managers in these facilities take measures to improve the nutritional quality and food intake of their elderly residents. Therefore, the purpose of this project was to assess perceived availability of healthy food choices and examine relationships between attitudes, subjective norms (SN), perceived behavior control (PBC), and behavior intention to consume healthy food at assisted-living facilities using Theory of Planned Behavior (TpB).

\section{RESEARCH DESIGN AND METHODOLOGY}

Prior to data collection, an approval to use human subjects in research was obtained from the Kansas State University Institutional Review Board.

\section{Participant Selection}


The target population was the elderly who are currently residing in assisted-living facilities in Kansas. There are 126 assisted-living facilities in Kansas, and 68 facilities are located within a 100-mile radius from Manhattan, KS. A randomly selected 26 directors of assisted-living facilities were contacted by a letter and follow-up telephone calls asking to participate in the study. Only those who have the cognitive ability to complete a survey and the capability of selecting and consuming food without assistance were invited to the study. Participants were to complete a written survey which was presented during a selected meal period.

\section{Instrument Development and Pilot Study}

The theory of planned behavior $(\mathrm{TpB})$ has been applied to different kinds of behaviors. Based on the assumption that choosing healthy food is under the volitional control of the individual, Ajzen's (1991) TpB was adopted to predict and explain the psychological processes of healthy food consumption intention. A survey questionnaire was developed based on TpB, literature review and an elicitation study.

The questionnaire included direct measures of respondents' belief of healthy food, perceived availability of healthy food, and attitudes (how elderly people feel about consuming health food), SN (perceived influences of other individuals around the elderly regarding consuming healthy food), and PBC (situations and conditions allowing or interfering with an individual's intention to consume healthy food) at assisted-living facilities. The definition of 'healthy food' was provided in the questionnaire as a reference for participants.

The questionnaire also included indirect measures based on the literature review and the elicitation study. For indirect measures of attitudes, five behavioral beliefs and outcome evaluation of each belief identified from previous studies (beneficial for health, helpful to control body weight, a wise decision, a pleasant experience and experiencing new things) were included. Indirect measures of attitudes were calculated by summed products across the belief strength and the outcome evaluation. Normative beliefs of four relevant groups (family members, friends, medical providers and cooks and foodservice staff) and motivation to comply were measured to calculate indirect measure of SN. Indirect SN was calculated by summed products across all normative beliefs and motivation to comply. Five control beliefs (adequate nutrition knowledge, adequately informed, adequate amount of advertisements, adequate number of choices available and easy to order) and their perceived power to influence behaviors were included in the questionnaire. Indirect PBC was calculated by summed products across all control beliefs and the perceived power.

The dependent variables of behavior intention to consume healthy food items at the facilities were included in the questionnaire. All questions used Likert-type scales. Demographic characteristics were also included in the instrument. The initial questionnaire was reviewed by a panel of foodservice and gerontology experts for content validity and clarity of directions. The questionnaire was revised and pilot tested with 15 elderly residents currently living in one of local assisted-living facilities. Inter-item reliability was examined using Cronbach's $\alpha(\alpha \geq 0.80)$. The questionnaire was revised again as appropriate. 


\section{Data Collection}

List of administrator telephone numbers were obtained from the Kansas Department of Aging website. Of 68 facilities located within a 100-mile radius from the research institution, 26 were randomly selected and contacted by researchers. Of 26, eight facilities agreed to participate in the study. The rest of facility administrators decided not to participant due to residents' medical reasons or lack of interest. The researcher and a graduate assistant set up an information table at the entrance to the dining room. Interested residents voluntarily visited the table where brief introduction of the study and methodology were presented. The residents completed the questionnaire during their meal time and dropped off the questionnaire at the information table as they leave the dining room. For those residents who needed assistance, either researchers or facility staff read and helped them in filling out the questionnaire. To increase participation, a bottle of hand soap was given to those completed the survey.

\section{Statistical Analysis}

Descriptive statistics (i.e., frequencies, means and standard deviation) were calculated to summarize the data. Each construct (i.e., attitudes, SN, PBC, and behavior intention) was calculated based on TpB handbook (CITE THIS) before employing further inferential analyses. Multiple linear regression analyses were applied to estimate the relationships between dependent variable (behavior intention) and independent variables. Data was analyzed using the SPSS for Windows Version 17.0 (2007, SPSS Inc, Chicago, IL) with $p<0.05$.

\section{RESULTS}

\section{Respondent Demographic Characteristics}

A total of 115 elderly residents of eight elder-care facilities provided usable data. The majority $(n=86)$ was females $(77.5 \%)$, and over $80 \%$ were 75 years or older. Almost all $(94 \%)$ respondents were Non-Hispanic White. About $40 \%$ of participants had a high school or GED education, $4.6 \%$ a Bachelor's degree, and $13.7 \%$ a graduate or professional degree. The majority $(\mathrm{n}=44)$ who indicated their annual household income made more than $\$ 30,000$. Sixty participants did not answer the question, possibly because either they felt the question was intrusive or they couldn't remember the information. Table 1 provides the demographic characteristics of the respondents.

\section{Table 1 Respondents' Demographic Characteristics}

\begin{tabular}{lcc}
\hline Characteristic & Frequency & Percent $(\boldsymbol{\%})$ \\
\hline Gender $(\mathrm{N}=111)$ & & \\
Male & 25 & 22.5 \\
Female & 86 & 77.5 \\
\hline Age $(\mathrm{N}=110)$ & & \\
55 or younger & 3 & 2.7 \\
$56-65$ & 4 & 3.7 \\
$66-75$ & 14 & 12.7
\end{tabular}




\begin{tabular}{|c|c|c|}
\hline $76-85$ & 35 & 31.8 \\
\hline 86 or older & 54 & 49.1 \\
\hline \multicolumn{3}{|l|}{ Race $(\mathrm{N}=105)$} \\
\hline Non-Hispanic Caucasian & 99 & 94.3 \\
\hline Non-Hispanic Black/African-American & 1 & 0.9 \\
\hline Native American (American Indians) & 3 & 2.9 \\
\hline Other & 2 & 1.9 \\
\hline \multicolumn{3}{|l|}{ Education $(\mathrm{N}=109)$} \\
\hline Less than High School or GED & 15 & 13.7 \\
\hline High School or GED & 44 & 40.4 \\
\hline Some college & 25 & 23.0 \\
\hline Bachelor's Degree & 5 & 4.6 \\
\hline Some graduate/professional work beyond Bachelor's degree & 5 & 4.6 \\
\hline Graduate or professional degree & 15 & 13.7 \\
\hline \multicolumn{3}{|l|}{ Household income $(\mathrm{N}=115)$} \\
\hline Under $\$ 30,000$ & 11 & 9.6 \\
\hline$\$ 30,001-\$ 50,000$ & 23 & 20.0 \\
\hline$\$ 50,001-\$ 70,000$ & 10 & 8.7 \\
\hline$\$ 70,001-\$ 90,000$ & 4 & 3.5 \\
\hline$\$ 90,001-\$ 110,000$ & 4 & 3.5 \\
\hline Over $\$ 110,001$ & 3 & 2.6 \\
\hline Did not answer & 60 & 52.2 \\
\hline
\end{tabular}

\section{Descriptive Statistics of TpB Measures}

The mean score of direct attitude measure was 4.28 with individual ratings ranging 4.10 4.43 in 5.0 scale (Table 2). Respondents rated "eating healthy food items in assisted-living facility is valuable" the highest $(4.43 \pm 1.05)$. The mean score of two direct measures of SN was 4.31 indicating that respondents thought most people whose opinions they value would approve of consuming healthy food items in the assisted-living facility. The mean of PBC measures was 4.11 with a range 3.90-4.29. Respondents rated "whether or not I eat healthy food items in the

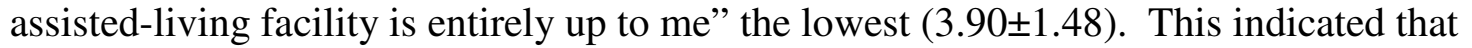
respondents perceived somewhat limited availability for them to consume healthy food choices in the assisted-living facilities. The mean score of behavior intentions was 4.27 indicating respondents planned to consume healthy food items in the assisted-living facility in the future.

Table 2. Summary of Direct Measurement Scales

\begin{tabular}{lr}
\hline Measurement items & Mean $^{\mathbf{a}} \pm \mathbf{S D}$ \\
\hline Attitude: Eating "healthy food items" in assisted-living facility & \\
is & \\
Valuable & $4.43 \pm 1.05$ \\
Good & $4.38 \pm 1.03$ \\
Useful & $4.36 \pm 1.38$ \\
Beneficial & $4.30 \pm 1.20$
\end{tabular}


Pleasant

$4.11 \pm 1.26$

Interesting

$4.10 \pm 1.35$

Subjective Norm (SN)

Most people who are important to me think I should eat healthy food

$4.53 \pm 1.47$ items.

When it comes to eating healthy food items in the assisted-living

$4.08 \pm 1.37$ facility, I would follow the advice of others who are important to me.

\section{Perceived Behavioral Control (PBC)}

If I want, I could easily eat healthy food items in the assisted-living

$4.29 \pm 1.17$

facility.

The choice to eat healthy food items in the assisted-living facility is

$4.15 \pm 1.29$

completely up to me.

Whether or not I eat healthy food items in the assisted-living facility $\quad 3.90 \pm 1.48$

is entirely up to me.

\section{Intention}

I plan to eat healthy food items in the assisted-living facility in the future.

I intend to eat healthy food items in the assisted-living facility in the

$4.27 \pm 1.22$ future.

${ }^{\mathrm{a}}$ Scale range from 1 (strongly disagree) to 5(strongly agree)

${ }^{\mathrm{b}}$ Standard Deviation

Specific belief items that influenced belief constructs are provided in Table 3. Attitudes are the overall sum of the belief strength multiplied by the outcome evaluation for each of the five beliefs. To calculate the attitude, one question was asked to measure behavioral belief and another was addressed the outcome evaluation. SN was represented by the overall sum of the belief strength multiplied by motivation to comply. Two questions were used to measure the SN, including one was associated with each normative belief and one for motivation to comply. As PBC was the overall sum of the products of control beliefs and perceived power, one question related to control beliefs and one question associated with perceived power were asked separately. Indirect measures with a range from -21 to 21 , which presents the strength of each variable. The higher number indicated the variable was more associated with behavior intention.

Among five behavioral beliefs, respondents rated "beneficial for health" $(19.72 \pm 6.63)$ as the most important. Having adequate nutrition knowledge $(18.80 \pm 6.63)$ was the highest perceived control factor affecting residents' healthy food consumption intention. Friends (15.03 $\pm 7.55)$ has the least influence on healthy food consumption intention among the four referent groups, which included family members $(17.86 \pm 7.43)$, medical providers $(19.26 \pm 7.91)$ and cooks and foodservice staff $(17.06 \pm 7.26)$.

Table 3. Descriptive summary of Indirect Measurement Scales

\begin{tabular}{lc}
\hline Measurement items & Mean $^{\mathbf{a}} \pm \mathbf{S D}^{\mathbf{b}}$ \\
\hline $\begin{array}{l}\text { Attitude } \\
\text { Beneficial for health }\end{array}$ & $19.72 \pm 6.63$
\end{tabular}


Helpful to control body weight

$19.13 \pm 7.07$

A wise decision

$19.28 \pm 6.57$

Experiencing new things

$18.08 \pm 7.27$

A pleasant experience

$18.20 \pm 6.97$

Subjective Norm (SN)

Adequate nutrition knowledge

$18.80 \pm 6.63$

Easy to order

$18.30 \pm 6.90$

Adequate informed about healthy food choices

$17.50 \pm 6.96$

Adequate number of healthy food choices available

$16.96 \pm 7.03$

Adequate amount of advertisements/marketing

$15.07 \pm 7.54$

\section{Perceived Behavioral Control (PBC)}

Medical providers

$19.26 \pm 7.19$

Family members

$17.86 \pm 7.43$

Cooks and foodservice staff

$17.06 \pm 7.26$

Friends

$15.03 \pm 7.55$

${ }^{\mathrm{a}}$ Scale range from 1 (strongly disagree) to 5(strongly agree) or 1 (extremely unimportant) to 5(extremely important)

${ }^{\mathrm{b}}$ Standard Deviation

\section{Analyses of Direct TpB Measures}

A multiple regression analysis explored the prediction of behavior intention based on direct measures of the residents attitudes, $\mathrm{SN}$, and perceived behavioral controls and found the model was significant $(\mathrm{F}=151.349, p<.001)$. The attitudes $(\beta=0.277, p<.001)$ and the $\mathrm{SN}$ $(\beta=0.633, p<.001)$ were significant in the model. However, the PBC was not found to be significant in the model.

Table 4. Multiple Regression Model for Predicting Behavioral Intention Based on Direct Measures

\begin{tabular}{lcccccc}
\hline \multicolumn{1}{c}{ Model } & Sum of Squares & df & Mean Square & F & Significance & $\mathbf{R}^{\mathbf{2}}$ \\
\hline Regression & 75.283 & 3 & 25.094 & 151.349 & $.000 * * *$ & .804 \\
Residual & 18.404 & 111 & 0.166 & & & \\
Total & 93.687 & 114 & & & & \\
\hline
\end{tabular}

Standardized Coefficients

\begin{tabular}{lcrl}
\hline \multicolumn{1}{c}{ Model } & Beta & \multicolumn{1}{c}{$\boldsymbol{t}$} & Sig. \\
\hline (Constant) & & -1.526 & .130 \\
Attitude & 0.277 & 5.415 & $.000^{* * *}$ \\
Subjective Norm & 0.633 & 10.062 & $.000^{* * *}$ \\
Perceived Behavioral Control & 0.042 & 1.708 & .090 \\
\hline
\end{tabular}

$* * * P<.001$.

\section{Analyses of Indirect TpB Measures}


A multiple linear regression was performed to examine the relationship between the attitudes, SN, PBC and behavior intention using indirect measures. Computed values of each construct were entered in the linear regression model. Healthy food consumption intention in the assisted-living facilities was predicted from indirect attitudes, SN and PBC. Consistent with the direct measure analysis, only the regression of the attitudes $(\beta=0.277, p<.001)$ and $\mathrm{SN}(\beta=0.633$, $p<.05)$ were significant in the model.

Table 5. Multiple Regression Model for Predicting Behavioral Intention Based on Indirect Measures

\begin{tabular}{lcccccc}
\hline \multicolumn{1}{c}{ Model } & Sum of Squares & df & Mean Square & F & Significance & $\mathbf{R}^{\mathbf{2}}$ \\
\hline Regression & 10.846 & 3 & 3.615 & 47.509 & $0.000 * * *$ & 0.697 \\
Residual & 4.718 & 62 & 0.076 & & & \\
Total & 15.564 & 65 & & & & \\
\hline
\end{tabular}

Standardized Coefficients

\begin{tabular}{lccl}
\hline Model & Beta & $\boldsymbol{t}$ & Sig. \\
\hline (Constant) & & 37.932 & 0.000 \\
InAttitude & 0.277 & 5.415 & $0.000^{* * *}$ \\
InSubjective Norm & 0.633 & 10.062 & $0.033^{* *}$ \\
Inperceived Behavioral Control & 0.042 & 1.708 & 0.174 \\
\hline
\end{tabular}

$* * * P<.001$.

$* * P<.05$.

$* P<.01$.

\section{DISCUSSION \& IMPLICATIONS}

In this study, TpB examined how residents' attitudes, SN, and PBC influence behavior intention for consuming healthy food choices in the assisted-living facilities. The results show that residents' attitudes, SN were positively associated with healthy food consumption intention in the assisted-living facilities. However, perceived behavioral control among residents was not a significant predictor of the intention to select healthy food choices.

The relationship between attitude and healthy food items consumption intention was significant and positive. Elderly assisted-living residents who have positive feelings about healthy food choices were more willing to consume healthy food, while those who have negatives or indifferent attitudes toward to healthy food and low behavior intention. According to Ajzen and Fishbein (1980), an individual will intend to perform a certain behavior when he/she evaluates it positively, and our results were consistent.

SN was also important in predicting elderly residents' healthy food consumption intention in this study. The elderly are more likely to evaluate the opinion of important others, and perform behaviors that others think important. This result is consistent with the finding of Wankel and Mummery (1993), who indicated that SN is associated with intention to do physical activity among elderly people. Additionally, Warburton and Terry (2000) found SN and intention 
to volunteer has a significant relationship. Elderly assisted-living residents who need assistant in daily life must stay closely with their medical providers, such as doctors, nurses, and other care providers and foodservice staff. Our results showed influence of family members, medical providers and cooks and foodservice staffs were greater than friends.

PBC has been found as an insignificant factor in this study. Results showed that elderly assisted-living residents perceived control ability about choosing healthy food choice in the assisted-living facility was not associated with their healthy food consumption intention. There are two possible reasons for no relationship between the two factors. First, when researchers asked if they are adequately informed about healthy food choices at the assisted-living facility and if there is an adequate number of healthy food choices available at the assisted-living facility, our participants stated that there is a lack of access to healthy food choices. One resident responded, "We don't have so much choice. We just eat what they give us." Another participant reported, "I never heard about any advertisements about healthy food choice in here. However, I don't want to make them look bad. I choose neutral." The second potential reason for the nonsignificant relationship between perceived behavioral control and intention may be due to biases from the data collection method. Some residents were not able to read the questionnaire and asked for help with filling out the questionnaire either from researchers or foodservice staffs in the assisted-living facility. Therefore, their true feelings about PBC may not have been correctly reflected by their answers.

The results of this study reconfirmed that elderly population living in elder care facilities desires and are willing to choose healthy food choices. While attitudes and SN were good predictors of behavior intention to select healthy choices, $\mathrm{PBC}$ was not found to be pertinent factor.

This study was the first to incorporate the $\mathrm{TpB}$ and conduct with the elderly to assess their intention to consume healthy food when residing in elder-care facilities. As Baby Boomers who are often characterized as independent, goal-oriented and more health conscientious getting older, administrators and managers from the assisted-living facilities need to be more aware of the needs and wants of these elderly in order to improve their quality of life. The results from this study provided a better understanding on the attitudes, perceived barriers, and behavior intentions of elderly living in assisted-living facilities toward healthy food consumption intention.

Managers from these facilities may be able to utilize this data to recognize their residents' needs, further investigate ways to improve residents' diets, and potentially increase healthy food consumption. Future researchers are recommended to explore ways to increase availability and consumption of healthy food choices in the assisted-living facilities, and eventually improve the overall quality of life for assisted-living residents.

One limitation of this study is the sample being assisted-living facilities in Kansas only. Thus, the results cannot be generalized to other facilities such as independent living, long-term care and nursing homes and facilities beyond Kansas. The second limitation is that the study did not explore the relationship between behavioral intention and behavior. Although behavioral intention cannot explain $100 \%$ actual behavior, studies have shown strong relationship between behavioral intention and actual behavior (Ajzen, 2002). TpB has been used to examine health- 
related intentions and decisions in numerous studies (Blue, 1995; Fishbein, 2006; Godin \& Kok, 1996; Fila \& Smith, 2006). Therefore, behavior intentions identified in this study may not directly reflect participants' actual behaviors. In the future, actual healthy food consumption data may be explored to increase validity of the model by evaluating association between behavior intentions and actual behaviors. Finally, this study did not address non-response bias. The facility directors who invited researchers into their facilities may be more aware of needs for healthy food choices; therefore residents of such institutions might already have more positive attitudes and social supports than those residing in facilities which were not included in this study.

\section{REFERENCES}

Access To Healthy Foods Coalition. (2009). Which foods does Access consider healthy or healthier? Retrieved from http://www.accesstohealthyfoods.org/index.php?page_id=213

Ajzen, I. (1991). The theory of planned behavior. Organizational behavior and human decision processes, 50, 179-211. doi:10.1016/0749-5978(91)90020-T

Ajzen, I. (2002). Perceived behavioral control, self-efficacy, locus of control, and the theory of planned behavior. Journal of Applied Social Psychology, 32(4), 665-683.

Ajzen, I., \& Fishbein, M. (1980). Understanding attitude and predicting social behavior. Englewood Cliffs, NJ: Prentice-Hall, Inc.

Baby Boomer Care. (2010). The baby boomers and the healthy industry. Retrieved from http://www.babyboomercaretaker.com/baby-boomer/The-baby-boomers-and-the-healthindustry.html

Blue, C. L. (1995). The predictive capacity of the theory of reasoned action and the theory of planned behavior in exercise research: an integrated literature review. Nursing \& Health, 18, 105-121.

Byrne, B. M. (1994). Structural equation modeling with EQS and EQS/Windows: Basic concepts, applications, and programming. Thousand Oaks, CA: SAGE Publications, Inc.

Centers for Disease Control and Prevention. (2009). Overweight and obesity. Retrieved from http://www.cdc.gov/obesity/index.html

Department of Health and Human Services and U.S. Department of Agriculture. (2005). Dietary guidelines for Americans 2005. Retrieved from http://www.health.gov/dietaryguidelines/dga2005/document/pdf/DGA2005.pdf

Fila, S. A. \& Smith, C. (2006). Applying the theory of planned behavior to healthy eating behaviors in urban Native American youth. The International Journal of Behavioral Nutrition and Physical Activity, 3(11), 1-10. doi: 10.1186/1479-5868-3-11

Fishbein, M. \& Cappella, J. N. (2006). The role of theory in developing effective health communications. Journal of Communication, 56, 1-17.

Godin, G. \& Kok, G. (1996). The theory of planned behavior: a review of its applications to health-related behaviors. American Journal of Health Promotion, 11(2), 87-98. 
Guenther, P. M., Reedy, J., Krebs-Smith, S. M., Reeve, B. B., \& Basiotis, P. P. (2007).

Development and evaluation of the healthy eating index-2005: technical report. Retrieved from http://www.cnpp.usda.gov/Publications/HEI/HEI-2005/HEI-2005TechnicalReport.pdf

Harvard Men's Health Watch (2006). Obesity in America: Large potions, large proportions. Retrieved from http://www.accessmylibrary.com/article-1G1-140668577/obesity-america-largeportions.html

Hautvast, J., De, G. L., \& Van, S. W. (1992). How food-related industries can respond to the nutritional needs of the elderly: A European view. Nutrition Review, 50, 484-487.

Kane, S. (2010). Baby boomers. Retrieved from

http://legalcareers.about.com/od/practicetips/a/Babyboomers.htm

Krout, J. A., Moen, P., Holmes, H. H., Oggins, J., \& Bowen, N. (2002). Reasons for relocation to a continuing care retirement community. Journal of Applied Gerontology, 236, 236-256. doi: $10.1177 / 07364802021002007$

Ogden, L. C., Carroll, D. M., Curtin, R. L., McDowell, A. M., Tabak, J. C., \& Flegal, M. K. (2006). Prevalence of overweight and obesity in the United States, 1999-2004. Journal of American Medical Association, 295, 1549-1555.

Patterson, I. R. (2004, February). Baby boomers and adventure tourism: An emerging market sector of pleasure seekers and risk takers. Paper presented at the Cauthe 2004: Creating Tourism Knowledge, Altona, Australia.

Wankel, L. M. \&Mummery, W. K. (1993). Using national survey data incorporating the theory of planned behavior: implications for social marketing strategies in physical activity.

Journal of Applied Sport Psychology, 5, 158-177.

Warburton, J., \& Terry, D. J. (2000). Volunteer decision making by older people: A test of a revised theory of planned behavior. Basic and Applied Social Psychology, 22(3), 245-257. 